Article

\title{
Forward-Looking Sustainability Agency for Developing Future Cruise Ships
}

\author{
Leena Jokinen ${ }^{1, * \mathbb{C}}$, Tuire Palonen ${ }^{2}$, Helka Kalliomäki ${ }^{3} \mathbb{C}$, Oana Apostol ${ }^{4}$ \\ and Katariina Heikkilä ${ }^{1}$ \\ 1 Finland Futures Research Centre, University of Turku, 20014 Turku, Finland; katariina.heikkila@utu.fi \\ 2 Department of Teacher Education, University of Turku, 20014 Turku, Finland; tuire.palonen@utu.fi \\ 3 School of Management, University of Vaasa, 65200 Vaasa, Finland; helka.kalliomaki@uwasa.fi \\ 4 Faculty of Management and Business, University of Tampere, 33100 Tampere, Finland; oana.apostol@tuni.fi \\ * Correspondence: leena.jokinen@utu.fi; Tel.: +358-4-0707-7982
}

Received: 30 September 2020; Accepted: 16 November 2020; Published: 19 November 2020

\begin{abstract}
The study addressed sharing of futures insights as a component of sustainability agency for long-term company enhancement in an interorganizational shipbuilders' network. The purpose was to analyze social structures under "agency" terminology. This joint sustainability project involved a partnership of firms, academia, and nongovernmental organization (NGO) actors in collaborative cruise ship building. The study adapted a mixed method approach where social network analysis (SNA) was enriched with other contextual data to make network data more applicable and accessible. The results revealed a loose and thin network structure, with relatively high trust among network actors. The network's social structure was found to facilitate insight sharing. Lead firm actors clearly played a central role in enhancing sustainability, and the researchers, as well as industrial association actors, made a significant contribution to insight sharing and transmission. The findings suggest that the case network would benefit from an open and balanced social structure that incorporates a number of insight brokers to enhance forward-looking sustainability agency (F-L SA). Futures insight sharing enhances agency in the context of joint sustainability actions and improves capacity to respond to systemic challenges. Understanding how proactive agency can be promoted in network settings strengthens strategic aspects of managerial practice and contributes to discourse around sustainability agency.
\end{abstract}

Keywords: sustainability agency; future; forward-looking; cruise ship building; social network analysis

\section{Introduction-Forward-Looking Sustainability Agency}

This paper explored how joint efforts to improve company sustainability are enhanced at network level through stakeholder collaboration, especially in terms of sharing futures insights. We defined company sustainability as context-specific organizational actions and policies that take into account stakeholders' expectations and the triple bottom line of economic, social, and environmental performance [1,2]. The main focus was on the personal relationships and social roles of actors in long-term sustainability agency. Agency for sustainability improvement has its roots in the idea of corporate responsibility as a collaborative effort and the associated need for collective agency to address the mismatched individual actions that lead to sustainability-related global challenges. Sustainability transition literature highlights the actions of intermediaries who are change agents and serve as a bridge between actors through knowledge transfer [3]. The present paper focused in particular on intermediaries who transfer futures insights and on their social positions and relationships as focal components of agency. 
Broadly defining sustainability agency as any form of dynamic dialogue or interaction between two or more partners, we contend that forward-looking agency drives sustainability enhancement. In this study, sustainability agency was explored from the futures research perspective in which the future is understood as being contingent and open, shaped by individual and collective actions [4]. The role of actors reflects relational agency, which is critical as actors' interaction initiate ideation for development and action [5]. According to Russel and Smorodinskaya, company sustainability has become interactive and collaborative, often a multidisciplinary and multidirectional process [6]. Rather than putting the focus on individuals' psychological attributes or life course variables, we highlighted social relations as the components and context for sustainability enhancement $[7,8]$. Our approach to sustainability agency focused on practice-level relationships and looks at company sustainability outside of immediate commercial value. Emphasizing collective agency, we incorporated the issue of uncertain futures into agency discourse, as this topic seems to be neglected in contemporary research on collaborative sustainability.

As maritime collaborative networks are less widely researched than, for example, networks in the construction industry or small- and medium-sized enterprises' (SMEs) innovation networks, less is known about the dimensions of sustainability in the maritime sector [9]. In the shipbuilding sector, company sustainability depends on the collective and coordinated actions of a wide range of collaborators to meet a new ship objectives. While the development of new ideas and collaborative innovation networks have been explored from various perspectives, innovation and research in the maritime industry have tended to focus more on technical and process innovations, and on large regional networks rather than collaboration between people and firms [10-12]. However, in a recent study of collaborative sustainability within the marine transport sector, sustainability, open innovation, and value co-creation networks were integrated into a model for a joint development. This research project highlighted the importance of an authentic co-creation of value and knowledge transfer among partners particularly in collaborations concerning futures [13].

The long-term futures perspective to sustainability agency highlights the importance of broad visions and unspecified goals or ideas for enhancement rather than specific solutions for improved sustainability performance or ways to fulfil certain sustainability indicators. Broadly defined, futures thinking can be understood as any thoughts that relate in multiple ways to possible futures. While it may address both long- and short-term timeframes, a long-term perspective is more relevant when analyzing or creating ideas to enhance sustainability $[14,15]$. For that reason, we adopted the term forward-looking to describe this flexible long-term thinking and the dynamic human orientation to futures [16]. We envisage forward-looking sustainability agency (F-L SA) as the complex interrelations of practical vision, ideation, knowledge creation, and reworking of the future beyond the limitations of earlier practices. In the present case, this is understood as the future perceptions, creative thoughts, and indeterminate perceptions of multiple future possibilities and their applications [17-19]. At the personal level, company sustainability includes forms of agency like sense-making, mutual learning, trust, and knowledge sharing [20]. This complexity of interpersonal ties and characteristics makes collaboration difficult to analyze from any single perspective [21].

To bring a futures perspective to bear on sustainability agency discourse and to contribute to the futures research literature, we explored how everyday practices and informal futures-focused development are constructed within a social network [22]. As much of the previous research has been statistical in nature, it has failed to capture how collaborative sustainability works at network level or what existing interorganizational structures might enhance future collaborative development on futures insight construction [23]. In particular, the significance of social ties in forward-looking analysis remains neglected in futures studies. By analyzing social network structures and actors' roles, we can better understand the role of agency in improving sustainability $[24,25]$. The present study developed such a methodology by locating actor relationships in the context of futures insight transfer. 


\subsection{Literature Review}

The collaborative nature of company sustainability (we adopted the concept of company sustainability because it is more commonly used in the case organizations than the term corporate responsibility) has become increasingly important in the contemporary business environment as intertwined companies more often collaborate to address sustainability challenges [26]. A review of the relevant literature served to identify key issues for sustainability collaboration in cruise ship building. In the multidisciplinary discourse around futures-focused sustainability within the marine sector, a long-term futures perspective is significant when planning a new ship. We found that the long-term futures perspective is substantial in the concept planning phase of a new ship [27]. F-L SA is embedded in everyday practices and done in informal ways and without using coherent foresight methodologies $[19,22]$. Motivation to look forward and a proactive attitude toward futures have been identified as significant drivers for sustainability agency [28,29]. In terms of human agency, F-L SA is linked to the initiation of new ideas, collaboration ties, insight sharing, and identification of future challenges for preferable futures [30-32]. For sustainability agency construction, the key attributes of social networks are advice seeking and trust between partners, which determines how much effort and commitment must be invested in collaborative development projects [33-35].

The rich literature on collaboration for sustainability reflects practical preoccupations for developing sustainability practices beyond organizational boundaries to include the entire upstream and downstream chain within which an organization operates [36]. Traditionally, this literature has been concerned mostly with organizational collaborations within the supply chain (SC), that is, in the upstream, but recent developments have pointed to the necessity to take a broader approach that would integrate customers and other stakeholder groups as part of the sustainability efforts [36,37]. The need to see sustainability as a comprehensive, systems-level phenomenon has led to efforts to distinguish businesses in terms of how deeply sustainability is embedded in their networks and their ways of working [38]. However, further work is needed to understand how business partner and other relationships (especially at the personal level) impact company sustainability and important activities like strategic planning $[36,39]$.

The research on social roles in sustainability partner networks has highlighted the role of a lead partner in the chain [40-42]. The leader in the chain uses its power to select such suppliers whose sustainability performance is in line with the leader's requirements. The leader also exerts a decisive influence on how sustainability is defined and which indicators or methods of evaluation are applied [40,43]. Research on collaborative company sustainability, which highlights equal dialogue among stakeholders, has stressed the central role of suppliers' independent self-directed development [44]. Networks and network actors contribute to company sustainability, collaborative agency, and systemic change by facilitating communication and knowledge flows [20], capturing and transmitting information of relevance to sustainability outcomes [29,45].

The basic collaborative actions are considered to be concrete collaboration, knowledge transfer, and mutual trust. These action categories are commonly used in the collaborative network literature $[6,20]$. The essential role in an F-L SA framework is a knowledge broker, which is a distinctive personal or organizational role within a social network [46-48]. Outsider types of brokers are identified by boundary-crossing social ties and their personal networks are less dense than those average network actors $[49,50]$. This diversity of social ties and network contacts enables brokers to access nonredundant information and increases their likelihood of acquiring ideas or other resources from different sources $[31,51]$ As outsider brokers have access to heterogeneous information and perceptions, they may also be sensitive to identifying needs and opportunities [25,32,52]. By bridging disconnected parts of the network, outsider brokers also play a role in controlling or mediating the flow of information and insights, and their own interests and ideas are likely to influence the nature of the information that reaches network members [25,53].

The key defining elements of a network form of organizing business partnership is based on trusting ethics [54]. Trust among network partners is also an essential part that facilitates futures 
insight transfer because sharing new ideas in interorganizational networks contains significant risk of opportunism and exploitation of ideas. Trust forms a basis of network partners' willingness to share knowledge and, correspondingly, a lack of trust may lead to competitive and secretive behavior. Free flow of futures insights happens in an atmosphere where partners do not need to protect themselves from others' opportunistic behavior [55]. F-L SA networks are based on collective actions to enhance sustainability and mutual trust is a prerequisite for collaboration. As a temporary community for building reciprocal understanding and intelligibility in the form of trust and solidarity, cooperation on sustainability ensures future gains for the whole network [56-58].

Futures research literature has emphasized the importance of the present decisions and views of futures for constructing preferable development [59]. The recent research stream of anticipation [60] highlighted the present actions as the means to construct the futures. Typically, the emergence of insights and ideation practices in the futures research literature has been based on understanding potential changes or possibilities from a broad perspective [61-63]. However, F-L SA is based on the idea that orientation to futures is grounded in innate human capacities and needs. It follows that forward-looking is an essential element of sustainability agency as a social activity where different members of an organization share insights regarding possible futures [64]. This, in turn, stimulates broadening circles for seeking radical new ideas $[30,65]$. Additionally, some approaches have emphasized the social nature of foresight as a process of participation among members of one or more organizations [19,66]. To that extent, the forward-looking perspective is embedded in the concept of company sustainability, although a futures orientation is not necessarily enacted in a structured or conscious way $[19,22]$.

With regard to knowledge sharing and emergence of insights, the futures research literature links forward-looking actions to long-term strategic analysis, dealing with uncertainty, human ability to foresee futures, and general attitudes to long-term futures $[62,67,68]$. Futures insight is understood as a set of beliefs, and generation of F-L SA is seen as a process in which network actors exchange and receive knowledge and are influenced by the knowledge and insights of others. As one component of futures insight, visionary knowledge construction goes beyond facts and empirical proofs. Ideas about futures are not constructed in a vacuum but exist in the minds of individuals, in dialogues with other people, and in various social contexts $[25,69,70]$. Futures-focused insights are a form of tacit knowledge, which can be more freely transferred in dense network structures that promote shared norms for cooperation and coordinated action $[33,34,71]$.

\subsection{Aim and Framework of the Study}

In the present study, our purpose was to develop a deeper understanding of F-L SA, as it is conceived within collaborative networks, and in doing so to render the concept of F-L SA more meaningful in managerial practice. We aimed to elaborate how collaboration on forward-looking is socially constructed and how futures insight sharing is promoted in a network setting. The goal was to explore connectivity between actors enhancing company sustainability as a form of futures insight construction.

The significance of the study is based firstly in addressing questions that drive and have an impact on company sustainability. We assumed that transparency of cooperation between business partners enhances possibilities for forward-looking practices for long-term collaborative development. Secondly, the study enhances the understanding of sustainability, not only in the context of the shipbuilding industry, but more generally in project organizations, and its findings will assist collaborative networks in their efforts to have productive dialogue and create value from company sustainability extending far into the future. Thirdly, it explains how F-L SA involves a socio-relational insight sharing process involving multiple actors. Although the importance of collective agency and social relations for long-term and complex change (including transitions to sustainability) is widely acknowledged, collaboration and insight transfer at the level of personal relationships is seldom addressed in maritime studies $[20,21,72]$. 
Based on three premises, we developed a theoretically informed F-L SA framework. First, to analyze a social space for agency as insight sharing within a network structure, we characterized the F-L SA space in terms of social cooperation and the ties, positions, and subgroups of close collaborators. Advice seeking and sharing were assumed to reflect forward-looking knowledge-in this case, futures insight sharing [73,74]. We further assumed that active collaborative efforts to enhance sustainability are context-specific strategic choices that are embodied more or less consciously in perceptions and visions of possible and preferred futures $[9,29,75]$.

Second, we argued that anticipating sustainability challenges or development needs are present actions of those with sufficient relational influence to foster ideas by pondering possible and preferred futures [60,76-78]. These present actions involve interactive collaborations for idea generation, definition, exchange of futures information, and tailoring visions of futures $[25,50]$. Trust between actors increases transfer of futures insights, and functioning partnerships stimulate mutual trust. The level of trust between partners determines the effort and commitment that must be invested in collaborative development projects and sharing of ideas [35,57].

Finally, we focused on the central role of individual actors and their social connections in insight sharing in social networks. As boundary-crossing actors, outsider brokers are ideally positioned to mediate insight flow and are fundamental to F-L SA, and exploiting their diverse connections and roles is therefore a key action point for forward-looking agency. As an inductive activity that encompasses the broad processes of futures idea generation, we argued that outsider insight brokers encourage futures insight generation through collaborative relationships and facilitate forward-looking agency by bringing ideas from outside the network [47]. The outsider broker can source novel ideas that affect how the network relates to futures possibilities and development needs. The diversity of these sources and social ties means that outsider brokers can have a significant impact on how actors perceive strategic options.

The F-L SA analytical framework presumes that the structure of social ties depends on ad hoc and nonhierarchical interaction rather than on nested structures. The futures research perspective adds depth to the framework in terms of a proactive attitude to futures and an emphasis on the concrete actions of advice sharing, collaboration, and trust building as essential elements of company sustainability. From a social network perspective, F-L SA highlights the roles of insight transfer and outsider brokerage. Figure 1 depicts the framework constructed on the basis of the literature that informed the analysis.
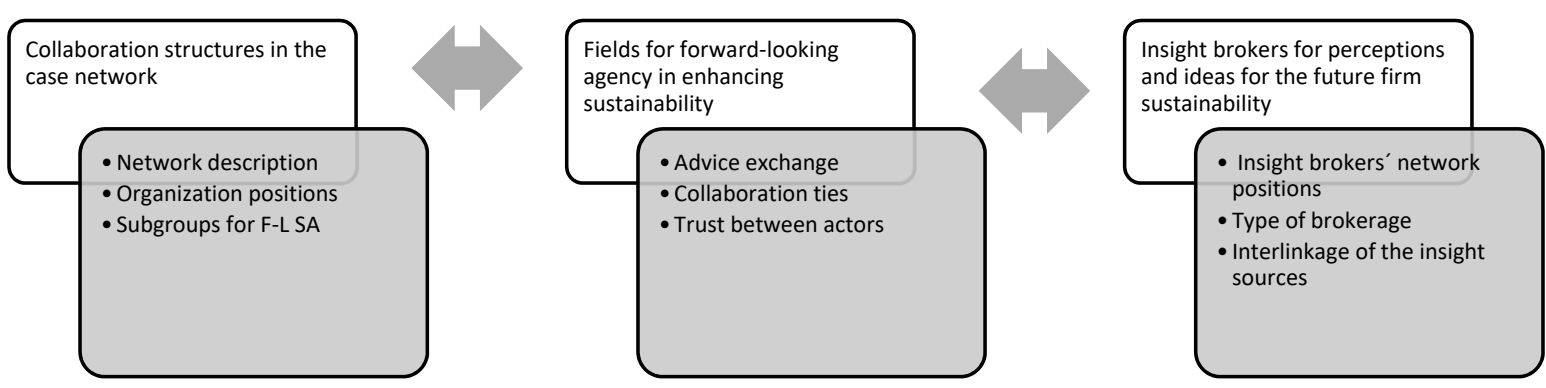

Figure 1. The framework for the forward-looking sustainability agency (F-L SA) in interorganizational company sustainability.

\subsection{Research Questions and Hypotheses}

We considered forward-looking insight sharing as tacit knowledge, which flows freely in dense, but decentralized network structures with high trust relationships [33,34,71]. Insight sharing implies integration of joint interest in the collective good, such as sustainability improvements from a long-term perspective. Aligning interests happens in the form of cooperation and expertise sharing, and this requires group solidarity, which is reflected as trust in social relations [57]. However, within an F-L SA network, tacit knowledge sharing happens in an interorganizational context, and therefore the overall 
network structure for F-L SA is sparse in collaboration and advice sharing, but contains a relatively high level of trust among actors [48].

The first research question was intended to examine how insight sharing for company sustainability is socially structured within the network by analyzing ties and relationships between individual actors. As such, the following hypothesis was offered:

Hypothesis 1 (H1). The F-L SA network structure is sparse with low density and centrality on collaboration and advice sharing, but denser in respect to trust relationships.

The research on individual actors' roles and positions [6,39] and the initiation of new ideas [30,31] has localized the agents and their organizational positions. The F-L SA focal action points were found to be insight transfer across organization or other subgroup borders [22,47,50].

The second research question focused on subgroups and insight transfer between them. We explored the subgroups within the network to find groups that collaborate, share insights, and drive sustainability on the operational level. Secondly, we hypothesized that subgroups consisting of boundary-crossing actors are formed within the network on the basis of mutual interest in interorganizational company sustainability. As such, the following hypothesis was offered:

Hypothesis 2 (H2). The F-L SA network has boundary-crossing subgroups consisting of actors who have similar roles or interests concerning company sustainability.

Actors who have a central position within an interorganizational F-L SA network are presumed to represent different subgroups, that is, the actor's background organization and project partner groups, to reflect collaborative efforts and heterogeneous advice sharing for sustainability. Sustainability agency is here compared to the role of an outsider insight broker, as a broker shares bodies of knowledge and encourages connections of actors from different organizations; in addition, they can also control insight flow [24,79].

The fourth question examined the central actors' positions within F-L SA network. We analyzed who the central actors are within the network and if they represent different positions and subgroups in order to enhance the insight flow in the whole F-L SA network. As such, the following hypothesis was offered:

Hypothesis 3 (H3). The central actors within the F-L SA network come from different background organizations and they represent different subgroups of a partner network.

We further examined the outsider type of insight broker roles in the case network to see if an outsider insight broker is an eminent role within the F-L SA network [46]. The outsider insight brokers operate in an interorganizational field and facilitate F-L SA by collecting and brining in ideas from diverse parts of the network as well as from outside; the outsider insight brokers play the role of an outsider mediator $[31,46,47,80]$.

The fourth question focused on outsider insight brokers' ties within the F-L SA network. We analyzed if external types of brokerage appear in F-L SA networks and explored connectedness of brokerage ties with the different groups within the network. We defined the outsider insight broker role as central in all dimensions: advice exchange, collaboration, and trust relationships, including boundary-crossing ties with different subgroups of the network. As such, the following hypothesis was offered:

Hypothesis 4 (H4). The F-L SA network has outsider types of insight brokers among the central actors. The outsider insight brokers have direct connections to every partner group of the network to mediate company sustainability enhancement. 
New and diverse external ideas have emerged from perceptions of potential changes and possible and/or preferable directions of development [61-63]. The versatile insight flow is an elementary feature of an F-L SA $[19,81,82]$.

The last research question explored the external insight flow into an F-L SA network. We examined how diverse the sources are used by the network actors, and we looked specifically at what sources the outsider insight brokers use and how diverse their sources are. As such, the following hypotheses were offered:

Hypothesis 5 (H5). The insight sources to enhance F-L SA are diverse and also emerge outside of the industry in question.

Hypothesis 6 (H6). The outsider insight brokers within the F-L SA network provide supplementary rather than overlapping insight sources.

\section{Materials and Methods}

\subsection{Case Study}

The research context was a shipbuilding network located in Finland. The lead firm produces luxury cruise ships and retains about 1500 employees. The nature of its complex products necessitates the use of a vast network of suppliers. The products, cruise ships, require intensive physical work but also employ a wide range of cutting-edge technological machinery. The lead firm has only recently started to organize its sustainability efforts. The different aspects of sustainability have gained different amounts of attention throughout the history of the firm, but a comprehensive mapping of them has been lacking. Occupational health and safety, environmental issues, and social responsibility have been the focus of the firm's sustainability efforts during recent years.

This research process started in early 2016 as a joint project between academic partners and the case firms to explore sustainability initiatives, practices, and their transparency, as well as the communication sustainability of the involved parties. The decision to enhance sustainability was strategically driven, the lead firm aiming to take the lead in an industry in which sustainability is considered as a discursive practice. Among the aims of the business, academia partnership was to elicit reflections on the role of sustainability for the entire network. The project consortium included the lead firm, first-tier and second-tier firms, a potential supplier firm, and two consultant companies. Research partners were the University of Turku (institutes of Future Technologies, Finland Futures Research Centre, and Centre for Collaborative Research) and the Technical Research Centre of Finland Ltd [VTT]. Additionally, three supporting partners representing an industrial association and suppliers were included in the project consortium. The consortium firm partners had their own subprojects supported by a joint research project. The case network studied here consisted of employees of the partner organizations, altogether 41 persons, who participated in the project by either interviewees, steering group members, nongovernmental organization (NGO) partners, or researchers.

The important stakeholders of any shipbuilding network are the end customers, NGOs (typically environmental NGOs), the authorities, and the communities located near the shipyard. The ship owner's end users are private customers and the ship's operational personnel. From the forward-looking perspective, shipbuilding requires early involvement of different partners and stakeholders to incorporate company sustainability ideas in a construction process, and thus these actors were also included in this study.

\subsection{Data and Analysis}

A network survey conducted in November 2018 gave us the main part of the data needed. The informants were the project actors involved with sustainability issues within their organizations. The survey was sent to the 41 case network members associated with of the project partners. The firm 
actors had been interviewed in an earlier phase of the project. Further, additional actors were added to the sample; at the end, the case network actors consisted of representatives of the participating firms' actors, researchers, and NGO actors involved in the project. The response rate for the network survey was good $(80 \%)$.

In the network survey, three questions were related to various network dimensions: collaboration, advice, and trust. Analysis was focused on the collaboration happening during the project actions, but not necessarily only the project actions, but rather, any interaction among the partners. The network questionnaire had a list of the names of actors, and the respondents were asked to assess the following: (1) from whom they sought advice regarding company sustainability, (2) with whom they collaborated, and (3) who they considered to be especially trusted partners. Additionally, respondents were asked to name other sources of insights into sustainability and its implications as well as whom they considered forerunners within sustainability in all fields or businesses. In addition, the network survey had two open-ended questions, which were designed to gather information related to such forerunners and collaborators who were not project partners, but represented whatever party or organization. Furthermore, we used field notes from the project meetings and seminars to support interpretations and add context understanding.

The study adapted a mixed methods approach where social network analysis (SNA) was enriched with other contextual data to make network data more applicable and accessible. Results from the SNA produced intuitive visualizations to reveal overall structures of the network. The other methods, in this case semi-structured interviews, added information on context of collaboration and company sustainability issues. Network data reflected individual-level results, such as the importance of cohesive network positions, mediator- and boundary-crossing roles, and the relationship between network and formal positions of the project actors [80]. With help of the SNA, we explored who had central roles, who shared knowledge or were asked for advice, and how mutual trust relations were distributed among partners. Structures of social networks were described by measures such as network density, centrality of actors, cohesion, and shape. Density means cohesiveness of partner ties, that is, the number of actors who are linked together. Centrality refers to the core of partners who have most of the ties. The concept of betweenness centrality refers to the number of times a node is in the shortest path between other nodes. Together, density and centrality measures indicate the level of connectedness of a network structure. The network shape makes visible the overall distribution of ties $[49,83]$.

SNA metrics were conducted via UCINET 6 software [84]. We used a whole network approach to describe the network structure and combined individual analysis to identify the central actors who had the most prominent positions within the case network. We also identified outsider types of insight brokers by their centrality and external connections to every project partner group (firms, research community, and NGOs). The description of overall structure of the network was done by determining the density of connections and relationships between individual actors and their organizations, in addition to actor centrality. The actor centrality was analyzed by the degree and heterogeneity of the ties. Degree centrality is a measure of the direct ties between one actor and other actors and it was used to analyze the role and position of an actor within the network. Subgroups that shared insights within the case network were analyzed by using Johnson's hierarchal clustering method of nodes. This connectedness method reorders pairs that are similar and joins them with other nodes into clusters until all the nodes are linked. The clustering iteratively constructs nodes by their similarities; here, subgroups are formed by actors' similar connections in advice sharing. A hierarchical clusters diagram, a dendrogram, plots the actors in clusters based on similarity of ties. Additionally, the futures knowledge and insight sources were analyzed in relation to the outsider insight brokers $[23,50,85]$. 


\section{Results}

\subsection{The Network Structure}

The network consisted of very heterogeneous relationships: project actors' personal relationships differed from the close partnership and personal friendship of relatively foreign persons with each other. Some of the actors in the case network did not actively take part in the project meetings or other actions, but could still collaborate on a daily basis, while other network members met mainly during the project actions, but did not have on-going collaborations. As a result, the data contain information on people who worked together varyingly within, and some even beyond, the project activities.

The density and centrality measures were analyzed for dichotomized networks, as well as overall description of the network structure, to describe how agency and insight sharing for company sustainability was structured within the case network. For the network dimensions, the density measures show a percentage of all possible connections: 100\% density means that everyone is connected to everyone, and $0 \%$ means that no one is connected to anyone. Centrality measures show the direction of connections: a 100\% value indicates a situation where all connections are targeted to one, the most central person, i.e., describing a network which is most centralized, and $0 \%$ described conditions where everyone share the same number of connections, i.e., describing a network which is the most decentralized [49].

The overall results of network structure analysis indicated that the case network structure was loose, a situation where all actors were somehow present and connected to some other actors. The network density revealed that, on average $(n=33)$, one person had 3.3 connections for advice sharing (density 8.2\%), 6.2 for collaborations (density 15.6\%), and 7.1 (density 17.7\%) for trusted relationships. The results showed a loose advice sharing network, collaboration and trust networks were denser than advice seeking, which was interpreted to reflect the collaborative project context. In practice, this means that the majority of the respondents collaborated with each other on some level. The collaborators for a certain ship project needed to link their actions to other partners' outputs. Also, the construction process timeline demanded considerable amounts of flexibility and co-ordination. Related to this, the density of collaboration and trust measures were on a moderate or solid level. All ties in reported network dimensions (advice, collaboration, and trust) were rather evenly distributed among participants, which was expected on the basis of field notes and observations during the project actions.

For centrality analysis, we focused on the actor ties and how much network ties were targeted to the same key persons with a leading role within the case network of 41 actors. The centrality measures (\% of all possible connections) showed a relatively low level of centralization: advice sharing being the most central dimension (27.5\%), while the collaboration (25.1\%) and trust relationships were the most decentralized (17.1\%), which revealed a rather decentralized network structure, as presented in Table 1 . The relatively low level of centralization combined with a loose network structure indicated weak and scattered ties for sustainability enhancement from forward-looking perspective within the case network.

Table 1. Density and centrality measures ( $\%$ of all possible ties, $n=33$ ) of the case network.

\begin{tabular}{cccc}
\hline Network Dimension & Advice & Collaboration & Trust \\
\hline Density & 8.2 & 15.6 & 17.7 \\
Centrality & 27.5 & 25.1 & 17.1 \\
\hline
\end{tabular}

To obtain an overall picture of the studied network, a 3D map of expert ties was generated (Figure 2). Experts, marked with spheres, were near to those experts with whom they shared advice, cooperation, or trust-sharing connections, that is, those whom they had picked from the list of names when replying to the survey. This meant all the nominations done to the questionnaire influenced the distances on the map. The lines between spheres indicate connections that were reported at least 
once. Therefore, a line can represent one or more connections between experts. The colors indicate to which group the actors belong (firms, NGO actors, or researchers). Those are persons who were mentioned frequently in network questions as having advice, collaboration, and trust connections. The eight actors with the highest numbers of links in the every network dimension were chosen as the central actors and indicated in the 3D map by bigger spheres. Thus, they represent central actors or communication knots of the case network. Among the central actors, the highest number of incoming ties in every dimensions were 44 and lowest value 24 ties, average was 16.5.

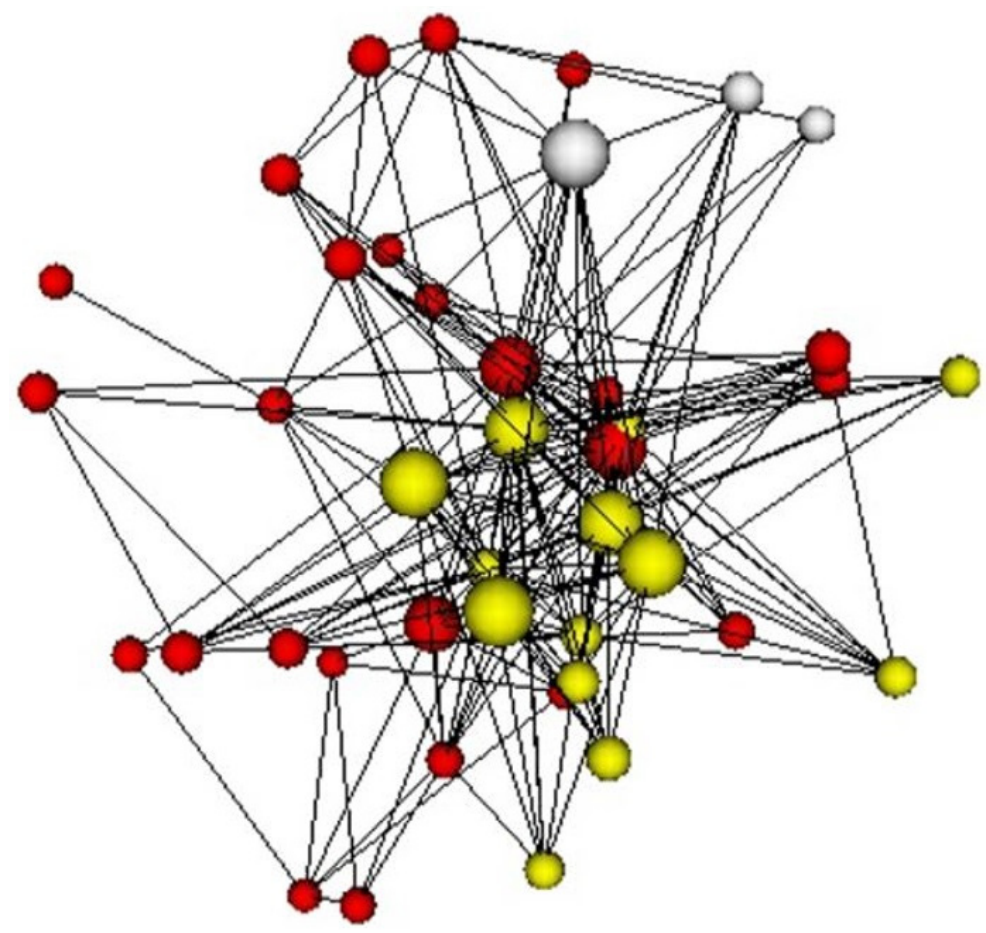

Firm actor $(n=25)$

Researcher $(n=13)$

NGO actor $(n=3)$

Figure 2. The case network ties as a 3D visualization (In the Supplementary Materials see a video of the network ties as a $3 \mathrm{D}$ visualization).

To conclude, for the first research question concerning the overall network structure for the F-L SA network being sparse for heterogonous insight sharing, we found that the case network structure met the expectation of decentralized structure for equal dialogue for sustainability improvements [39]. We found that the actors in the case network had a relatively high level of mutual trust (see Table 1), which also indicated the possibility to exchange ideas in an interorganizational network [48]. However, the case network was focused around the research community, with the majority of central actors being researchers. The firm actors were observed as a loose and somewhat distributed network around the core of the research community. The shape of the case network showed the heterogeneity in distribution of ties among the actors. Some firm actors bridged other experts in the network. Based on these findings on the case network, we validated $\mathrm{H} 1$.

The overall structure of the case network showed that there was not anyone too far away from the core of the network map. This result is regarded as positive in terms of insight flow and new idea generation, with the conclusion not being self-evident. All participants had at least some level of activity on company sustainability and connectivity within the case network.

\subsection{Subgroups within the Network}

We studied the subgroups within the case network, firstly, by actors' background organizations (groups of firms, researchers, and NGOs), and secondly, by hierarchical clustering. Individual-level information was left out from the results to guarantee the anonymity of the respondents. The number 
of NGO actors was low (three actors) because that percentage was not reported, but connections were described separately.

Within the firm actor group, the advice sharing density rate was low $(7 \%, n=25)$, which meant that firm partners did not commonly seek advice from other actors, while for the research actors, the density was higher $(29 \%, n=13)$. The firm's position in the SC was linked to advice sharing ties-the lead firm actors had roles as prominent advice providers. Three lead firm actors had altogether 20 incoming ties for advice seeking. The researchers had individually $2-10$ incoming advice seeking ties, mostly from other the researchers. Of the NGO actors-mainly industrial association partners-two persons had altogether 10 incoming ties. Collaboration density inside and between groups was somewhat higher than advice seeking: collaboration density within firm actors was $11 \%(n=25)$, while density between researchers was high $(61 \%, n=13)$. The firm's position in the SC was understandably linked to the collaboration ties: the collaboration ties with the lead firm actors (three actors) had 20 incoming collaboration ties. The NGO actors (three actors) were actively mentioned as collaboration partners with 17 incoming ties. The researchers had individually $8-10$ incoming collaboration ties, again mostly with other researchers. The trust network was densest within the subgroups as it was within the entire network level. This fact reflects the important role of trust in interaction and communication on futures possibilities in the F-L SA network [23].

The lead firm actors had a prominent role, especially in the collaboration network, but also as advice providers. The researchers had close collaborative ties, and they sought advice and insights from each other. The firm actors did not report the researchers' influence on the sustainability enhancement in the form of advice seeking within the firms. We found that the collaboration ties were loose across organizations, but tighter in ongoing collaborations between established actors. The project actions had obviously promoted collaborative ties between researchers across their organizations, but not much between firm actors.

To look deeper into the insight sharing in the form of advice sharing between the subgroups, we analyzed actor centrality separately from their background organizations to find out to what extent the actors' connections transcended the organizational boundaries or where the subgroups also divided according to the background organization. We used a hierarchal clustering method to find subgroups for advice sharing. The hierarchal cluster diagram, a dendrogram, shows hierarchical relationships and cluster case network actors together based on the similarity of advice sharing ties. The actors in the same groups had similar connections (see Figure 3). The three relatively big clusters were found with similar actor ties: cluster A consisted mainly of firm actors and one researcher, cluster B had a diverse structure, and cluster $\mathrm{C}$ had mainly firm actors. The NGO actors were in different clusters. In addition, four small clusters were found, with three of them mainly researchers' groups and one mixed researcher and firm actor group.

As a result, we concluded that the ties for advice sharing were not mainly divided by the actors' background organization, and that even some of the researchers seemed to have similar ties. The hierarchical cluster construction was apparently linked to the actors' role in the case network, either having a strong coordinating/managerial or a minor subordinate role and expertise on sustainability. Thus, $\mathrm{H} 2$ was validated, as the majority of the subgroups had somewhat diverse structure, indicating other similarities that the actor's background organization.

To conclude, we found that F-L SA is linked to an actor's background organization in the form of collaboration and advice sharing. The personal advice sharing and collaboration ties tended to concentrate on the nearest colleagues within the same organization. The leading firm actors seemed to be key players to enhance company sustainability, even when the case network had researchers who were in a central position. Our empirical findings suggest the need to strive for more open insight sharing within the case network. On a general level, we concluded that advice flow between relatively big and diverse groups of actors is a prominent feature for an F-L SA network. 


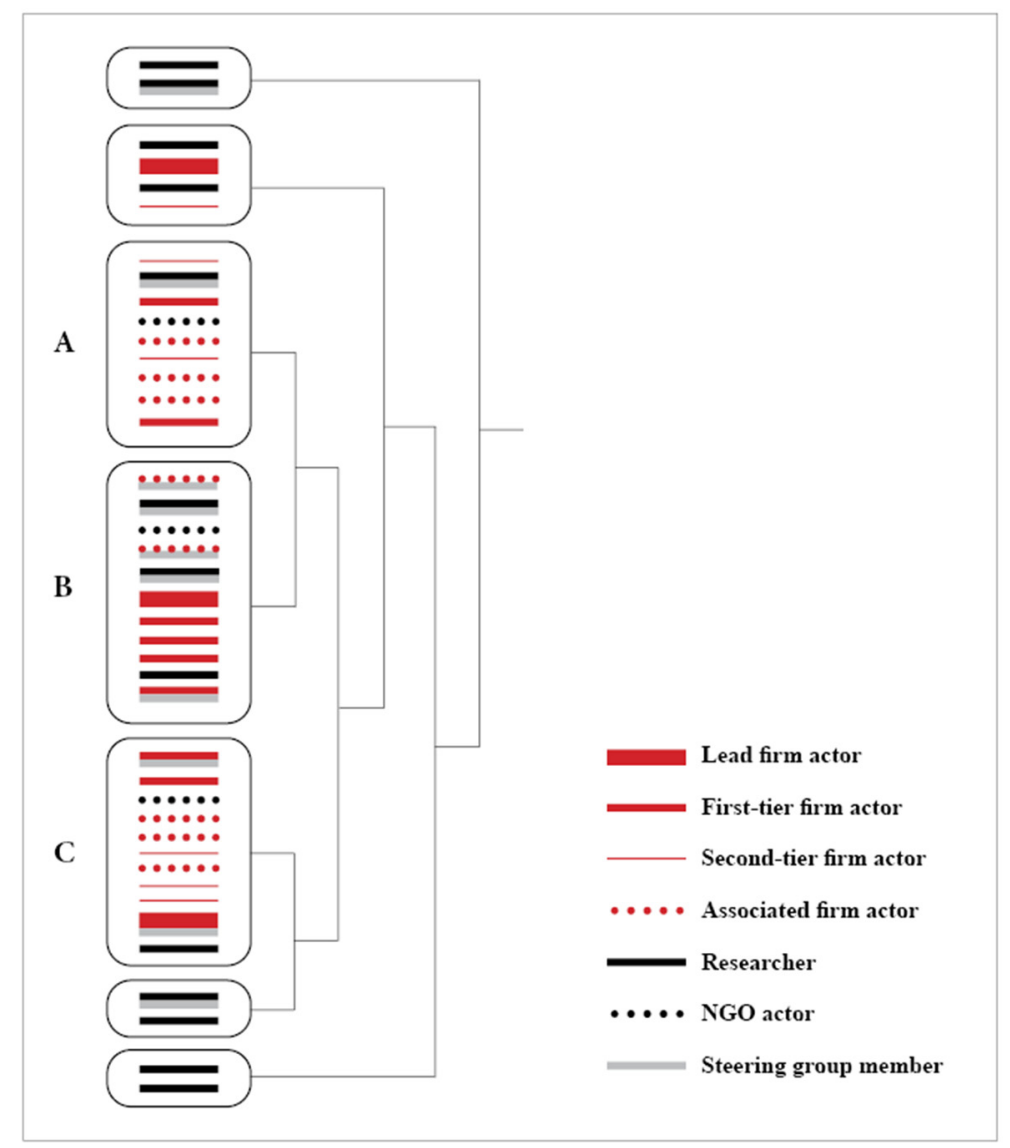

Figure 3. Dendrogram for the advice seeking/giving clusters.

\subsection{The Central Actors and Outsider Insight Brokers within the Case Network}

Our field notes suggested that there were ambiguous expectations for a leader and guidance in building company sustainability. The suppliers seemed to wish for clear guidelines for which sustainability improvements are needed in specific products or services. On the other hand, the lead firm actors wished for initiatives from the suppliers and other stakeholders. In the end, a ship owner's concept and specifications were expected to provide guidelines for sustainability improvements. We studied individual actors' personal networks as a part of the whole network and the heterogeneity of their ties. We aimed at to clarify who were the central actors and who possessed proactive agency within the network to highlight multiplex contexts of collaboration on sustainability enhancement among case network actors (see Table 2). We examined central actors' roles and positions further to add understanding around the concept of sustainability work at the company level. We identified nine persons by highest degree of incoming links ( $>24$ ties) altogether across all dimensions. Moreover, the results showed whom the others perceived as the sustainability experts and proactive actors, as well as who were the reactive receivers of insights. Table 2 summarizes the results for the most central actors. 
Table 2. The central actors: their network size (number of ties).

\begin{tabular}{cccccc}
\hline $\begin{array}{c}\text { Central } \\
\text { Actors } \\
\text { Node \# }\end{array}$ & $\begin{array}{c}\text { Advice } \\
\text { In-Coming Ties }\end{array}$ & $\begin{array}{c}\text { Cooperation } \\
\text { In-Coming Ties }\end{array}$ & $\begin{array}{c}\text { Trust In-Coming } \\
\text { Ties }\end{array}$ & $\begin{array}{c}\text { In-Coming Ties } \\
\text { Sum for All } \\
\text { Dimensions }\end{array}$ & $\begin{array}{c}\text { Out-Going Ties } \\
\text { Sum for All } \\
\text { Dimensions }\end{array}$ \\
\hline LFS5 & 14 & 16 & 14 & 44 & 19 \\
NS28 & 8 & 12 & 13 & 33 & - \\
RS36 & 3 & 10 & 14 & 27 & 54 \\
RS32 & 10 & 9 & 9 & 27 & 33 \\
RS33 & 5 & 11 & 11 & 27 & 16 \\
FS6 & 6 & 8 & 10 & 24 & - \\
R37 & 8 & 7 & 9 & 24 & - \\
F10 & 7 & 10 & 9 & 24 & 24 \\
R41 & 4 & 10 & 9 & 24 & - \\
\hline
\end{tabular}

Note. $\mathrm{R}=$ researcher, $\mathrm{F}=$ firm actor, $\mathrm{LF}=$ lead firm actor, $\mathrm{N}=$ nongovernmental organization (NGO) actor, $\mathrm{S}=$ steering group member, $\#=$ node number.

Most of the central actors were members of the project's steering group-six persons out of nine. The two most central actors were the lead firm's employee with managerial positions and the NGO actor. Altogether, five of the central persons belonged to the researcher group, but only one of them got a high value for advice seeking ties. In the data, there were five persons whom no one had nominated as an advice provider. They were firm actors: two first-tier suppliers and a second-tier supplier, in addition to an NGO actor. Our analysis showed that even the central actors had a relatively low number of ties and thin connections within the case network, as the lowest number of in-coming ties was three in advice seeking. The result indicates that advice sharing on sustainability improvements has not been very active within the case network.

Based on these analyses, we validated H3. The central actors within the case network represented the different background organizations and they were involved in different subgroups within the case network. The prominent role of the lead firm's actor was clear within the central actors group, but still the central actors' ties were based on informal nonhierarchical relationships, and especially the firm and NGO actors' ties were organizational boundary-crossing. Nevertheless, the firm actors representing suppliers had scattered ties and had no one central in the case network. The central researchers had an active role in contacting other actors and collaborating with colleagues. The proactiveness of the central actors was analyzed in the form of external insight sources and are reported in Section 3.3.

We further analyzed insight sharing by looking at outsider insight brokerage within the case network. The definition of an outsider insight broker in the case network was established based on the centrality of the actor and nominations in an advice provider role $(10<$ incoming ties average 3.3), and background organization boundary-crossing ties (see Table 3). Based on these criteria, we identified two outsider insight brokers who were central, that is, having $25 \%$ of all respondents ( $n=33$ actors) nominating them as an actor from whom they sought advice on company sustainability. The outsider insight brokers had boundary-crossing ties with actors from all partner group: firms, researchers, and NGO groups. The two outsider insight brokers found were the lead firm actor and a researcher, and both were also members of the project steering group. As a result, it can be assumed that outsider insight brokers had gained their role through both their formal position and expertise on company sustainability.

Thus, we validated H4. as the case network had outsider types of insight brokers who were connected to the actors from different background organizations. However, none of the actors amongst NGOs and the firm actors representing first- or second-tier suppliers were in the role of outsider insight broker. The number of outsider insight brokers was expected to be higher based on the objectives of the case project. The low number of outsider insight brokers indicated that the project actions were organization-specific and that the collaborative agency to promote insight sharing was not a very actively recognized function of the project. We concluded that sharing of insights was an underused resource as connections across organizational borders were limited. 
Table 3. The external insight sources nominated. Type of the source and number of nominations.

\begin{tabular}{cc}
\hline Type of Insight Source & Total Number of Nominated Persons or Organizations \\
\hline Colleague in respondents own organization & 7 \\
Partnership includes customer relationship & 8 \\
Benchmark company & 5 \\
Governmental authority & 12 \\
University, research institute, or consultancy agency & 11 \\
NGO such as industry associations & 8 \\
Visionary persons & 5 \\
Total & 56 \\
\hline
\end{tabular}

\subsection{External Sources for Futures Insights}

External sources of forward-looking sustainability insights were asked for in the open-ended question. The response rate to this question was relatively low (45\%): 17 persons out of 41 nominated at least one source from which they looked for futures insight outside of the case network. The responses were firstly documented and sorted by the type of organization of the external insight provider; secondly, nominated individuals or organizations were classified by the number of nominations and interconnected ties.

Altogether, 40 different organization or groups, and 56 names of persons were mentioned as sources for futures insights. The most commonly mentioned persons represented regulatory authorities, such as the Finnish Transport Safety Agency [Trafi], Prime Minister's Office, Ministry of the Environment, Finnish governmental sustainability company [Motiva], and the International Marine Organization. Many of the external insight providers came from universities, research institutions, and consultancy agencies. Most often, the researchers nominated colleagues from their own organization or other universities. International associations and NGOs also played a significant role as a source for futures insights. Among the associations mentioned were the Baltic Marine Environment Protection Commission (Helsinki Commission [HELCOM]), Sea Europe, and the International Association of Classification Societies. Only some (five different nominations) benchmark companies and visionary persons (five individuals) were nominated as an external insight provider. The number of external insight providers the project actors shared were few; the most nominations were for persons from the regulatory authorities and from the partner firms. Table 3 summarizes the key results of the futures insights source types.

To clarify who were the external insight providers for company sustainability outside the case network, we state that the forward-looking information seemed emerge mainly from the authorities, associations, and research institutions. Insights concerning sustainability development were also sought from business or research partners (see the Table 3). Interestingly, the researchers did not have any interlinked connections, but every researcher nominated different sources, even though the researchers formed a dense group. Most of the connections to the sources seemed to be reactive in the sense of following the regulations and association suggestions in the maritime fields, rather than proactively looking beyond the industry, with few exceptions. The insight sources used were mostly the "business as usual" type of sources, and few (five) visionary actors were mentioned. New insights seemed to have emerged from industry-specific sources. The firm actors specifically looked inside the industry, while the researchers mentioned sources outside of the maritime sector. Ideas for F-L SA in the case network came from relatively meagre sources, rather than from those with open and general long-term futures views.

The central actors had a major role in forward-looking insight gathering within the case network as they mentioned the majority (40 out of a total of 56) of the insight sources. However, the insight flow did not necessarily reach every node in the network, as most of the central actors were researchers who collaborated with colleagues. The central actors' role in forward-looking idea sharing and proactive attitudes had significance for the whole network. As most of the central actors' had relatively small and thin networks in advice sharing, we concluded that insight flow from external 
sources for forward-looking sustainability had a rather minor role within the case network. The case network's two insight brokers especially promoted the business partners' perspective to the case network. Thus, we were unable to completely validate H5. In fact, the central actors used several external sources also outside of the maritime industry. However, the insight brokers' sources were sector-specific, and only a minority of the all case network actors' insight sources came from outside the maritime sector.

To look deeper into the diversity of the insight sources, we analyzed if the external sources were the same and if there was a versatile flow of ideas provided by the insight brokers. We could not find overlapping social circles where the two insight brokers were involved and their sources were different from each other.

Based on these conclusions, we validated $\mathrm{H} 6$ as the sources for the insights differed from each other and were supplementary rather than overlapping. We concluded that, at least in some sense, the external insight flow and the sources were somewhat diverse at the case network level, even the sharing of the insights was a minor role in the project. However, we must note that the data did not permit us to make any definite assertion about the diversity of sources that were brought into the network as the response rate was low and the researchers were dominant in mentioning sources.

We conclude the findings of the F-L SA network tested in the context of the case network by evaluating results according the analytical framework presented in the Figure 1 and the hypotheses drawn on basis of the prior literature. Firstly, we found support for hypothesis one and two of the heterogeneous and sparse network structure, which allows multiplex interaction among the actors. The case network showed trust to be denser than other dimensions and none of actors were isolated and far from the core of the network map. Secondly, concerning hypotheses three and four, we found boundary-crossing subgroups, which had diverse structures to indicate positive facilities for insight sharing across organizations. However, our results showed clearly the focal role of the lead firm partners in the case network, indicating that relationships between actors was not in balance, as presumed within an F-L SA network. Thirdly, we found some evidence for hypotheses five and six, that the sources of insights were diverse and amongst the central actors there were outsider types of insight brokers. As a whole, the results showed the weak role of F-L SA within the case network and defectiveness of futures-focused mindsets in sustainability enhancement.

\section{Discussion}

In the shipbuilding context, company sustainability offers a rich test bed as a collaborative space for forward-looking development, in which sustainability enhancement entails far futures, multiple strategic and human resources touchpoints, and operations-level development. In line with earlier research, the case network actors themselves highlighted the importance of long-term partnerships, close person-level communication, and shared mindsets as important resources and elements of opportunity spaces $[86,87]$. The results serve to clarify how F-L SA analysis can promote agency for collaborative endeavors.

We established that the collective form of F-L SA depends on the involvement of diverse actors from multifaceted organizations to produce an equal and open dialog in contexts where the supply chain leader is dominant. This finding confirms the importance of balance in the roles and social structure of intermediaries and change agents to ensure that the chain leader alone does not determine the direction of sustainability change. Our results indicate that while suppliers organize around the supply chain leader and industrial associations, they are much less open to academics and other outsiders. This means that the flow of new insights and suppliers proactive agency may be diminished if they are not aware of potential drawbacks and obstacles of their sustainability agency on a microlevel. $[8,20]$.

The theoretical interest of this study relates to the idea of loose and heterogeneous networks as a space or platform for creating new ideas and building forward-looking collaborations [31]. Our results highlight the importance of social ties as building blocks of sustainability agency for operations-level foresight or forward-looking analysis, which remains a neglected issue in the futures 
research literature. Although rarely used in futures research, social networks analysis can provide valuable information (for example, when constructing Delphi panels and selecting futures workshop participants), as this method provides more detailed information about actors' positions and roles in the network. Our integrative research design combined collaborative sustainability, social network analysis, and futures research, incorporating a forward-looking perspective for a holistic understanding of F-L SA. This approach offers practitioners several means of improving sustainability-for example, by combining ideas from different collaborators and integrating diverse futures insights in the ship concept planning phase. The network structure and actors' ties are prerequisites for equity-based, high-trust collaborative relationships and free sharing of forward-looking ideas [88].

We contend that earlier findings regarding the significance of interorganizational partner relationships that are equal, deep, frequent, and intense need to be extended by adopting a forward-looking perspective $[20,50,89]$. As we have shown, the F-L SA approach facilitates substantial knowledge flow enhancement for company sustainability. The implications of forward-looking insight sharing creates an expectation of richness and diversity of idea providers from outside the industry $[29,81]$. Clearly, those external idea providers ensure the heterogeneity of social ties and require network actors to become more receptive [90-92]. This openness to diverse ideas adds dynamically changing ties and challenges firms to manage sparse collaboration networks. Wider participation and interactive insight construction beyond the influence of central actors contribute to an ideal model for foresight networks and should inform future collaborative actions for enhancing F-L SA [29].

Our findings have two main implications. First, our results highlight the lack of recognition of F-L SA challenges within the case network. Based on our network analysis, we argue that a less centralized structure (around the lead partner) would benefit the network as a whole in terms of collaborative agency and responses to other systemic sustainability challenges. There is also a clear need to develop multifaceted stakeholder interaction. One possible route toward collaborative network cohesion would be to explore how actors share resources-that is, how insight brokerage functions in everyday work. Helping network actors to identify long-term changes and their implications at a local level demands a space in which novel ideas can emerge and be explored in a context-specific way [19]. Secondly, the F-L SA network is a potential resource that can be used more consciously in the future across different project-based industries. By highlighting proactive network-level agency, we have augmented the agency concept to include uncertain futures and the capabilities needed to explore them.

Our study has some limitations, some of which suggest paths for further research. The case study was context-specific, and we acknowledge that other collaborative sustainability settings may have different network dynamics. For that reason, the F-L SA framework should be tested in different project-based businesses involving complex products. Additionally, the investigation of forward-looking insight sharing should indicate how futures-focused these insights actually are, and how futures-literate the actors are in assessing forward-looking qualities [60,78].

To build and validate a theory of F-L SA, qualitative methods should be supplemented by further research and wider quantitative testing. Future studies on forward-looking collaborative agency should also investigate what foresight capacities an organization or a network needs in order to use social resources effectively. Future research on foresight systems should therefore explore the interplay between the organization and the open interorganizational network in order to understand the linkages between capabilities and/or willingness to collaborate on forward-looking actions. While the tension between the positivistic foresight approach and the dynamic nonlinear nature of forward-looking approach remains a matter of debate [22], forward-looking agency as a process of nonlinear collaboration can inform exploration of preparedness for future disruption. The immediate challenge is to develop better ways of capturing the role of socio-relational structures in insight construction and sharing.

Supplementary Materials: The following are available online at http://www.mdpi.com/2071-1050/12/22/9644/s1, Video S1: The network ties as a 3D visualization. 
Author Contributions: Conceptualization, writing—original draft preparation, methodology, formal analysis by L.J.; methodology, formal analysis, writing-review and editing, supervision by T.P.; writing-review and editing by H.K., O.A., and K.H. All authors have read and agreed to the published version of the manuscript.

Funding: This research was partly funded by Business Finland, grant number 2180/31/2017. Oana Apostol acknowledges the financial support from the Academy of Finland research project (decision no. 324215) under the leadership of Eija Vinnari.

Acknowledgments: We acknowledge the support and cooperation of all the project partners. We wish also to thank the two anonymous reviewers who helped us to improve the quality of the paper.

Conflicts of Interest: The authors declare no conflict of interest. The funders had no role in the design of the study; in the collection, analyses, or interpretation of data; in the writing of the manuscript; or in the decision to publish the results.

\section{References}

1. Üstündagli, E. Collaborative sustainability: Analyzing economic and social outcomes in the context of cittaslow. Bus. Econ. R. J. 2015, 6, 125-144.

2. Wettstein, F. Corporate responsibility in the collective age: Toward a conception of collaborative responsibility. Bus Soc. Rev. 2012, 117, 155-184. [CrossRef]

3. Kivimaa, P.; Boon, W.; Hyysalo, S.; Klerkx, L. Towards a typology of intermediaries in sustainability transitions: A systematic review and a research agenda. Res. Policy 2019, 48, 1062-1075. [CrossRef]

4. Bell, W. Foundations of Futures Studies: Human Science for a New Era; Transaction Publishers: New Brunswick, NJ, USA, 2004.

5. Burkitt, I. Relational Agency: Relational Sociology, Agency and Interaction. Eur. J. Soc. Theory 2016, 19, 322-339. [CrossRef]

6. Russell, M.G.; Smorodinskaya, N.V. Leveraging complexity for ecosystemic innovation. Technol. Forecast. Soc. Chang. 2018, 136, 114-131. [CrossRef]

7. Koistinen, K.; Teerikangas, S.; Mikkilä, M.; Linnanen, L. Active sustainability actors: A life course approach. Sustain. Dev. 2019, 208-223. [CrossRef]

8. Gond, J.; Moser, C. Critical Essay: The reconciliation of fraternal twins: Integrating the psychological and sociological approaches to 'micro' corporate social responsibility. Hum. Relat. 2019, 1-36. [CrossRef]

9. Cheng, T.C.E.; Zanjirani Farahani, R.; Lai, K.; Sarkis, J. Sustainability in maritime supply chains: Challenges and opportunities for theory and practice. Transp. Res. Part E Logist. Transp. Rev. 2015, 78, 1-2. [CrossRef]

10. Xue, X.; Zhang, R.; Yang, R.; Dai, J. Innovation in construction: A critical review and future research. Int. J. Innov. Sci. 2014, 6, 111-125. [CrossRef]

11. Kujala, P.; Lu, L.; Lu, L. Marine Design XIII. In Proceedings of the 13th International Marine Design Conference (IMDC 2018), Helsinki, Finland, 10-14 June 2018; CRC Press: Boca Raton, FL, USA, 2018.

12. Shi, Y.; Lin, W.; Chen, P.K.; Su, C.H. How can the ISO 9000 QMS improve the organizational innovation of supply chains? Int. J. Innov. Sci. 2019, 11, 278-298. [CrossRef]

13. Rupo, D.; Perano, M.; Centorrino, G.; Vargas-Sanchez, A. A Framework Based on Sustainability, Open Innovation, and Value Cocreation Paradigms-A Case in an Italian Maritime Cluster. Sustainability 2018, 10, 729. [CrossRef]

14. Cole, S.; Kvavilashvili, L. Spontaneous future cognition: The past, present and future of an emerging topic. Psychol. Res. 2019, 83, 631-650. [CrossRef] [PubMed]

15. Piirainen, K.; Gonzalez, R. Theory of and within foresight—-What does a theory of foresight even mean?”. Technol. Forecast. Soc. Chang. 2015, 96, 191-201. [CrossRef]

16. Havas, A.; Weber, K.M. The 'fit' between forward-looking activities and the innovation policy governance sub-system: A framework to explore potential impacts. Technol. Forecast. Soc. Chang. 2017, 115, 327-337. [CrossRef]

17. Seginer, R. Future Orientation: A Conceptual Framework; Springer: Boston, MA, USA, 2009.

18. Cuhls, K.; Uerz, G. From forecasting to foresight processes-new participative foresight activities in Germany. J. Forecast. 2003, 22, 93-111. [CrossRef]

19. Weber, C.; Sailer, K.; Katzy, B. Real-time foresight-Preparedness for dynamic networks. Technol. Forecast. Soc. Chang. 2015, 101, 299-313. [CrossRef] 
20. de Haan, F.J.; Rotmans, J. A proposed theoretical framework for actors in transformative change. Technol. Forecast. Soc. Chang. 2018, 128, 275-286. [CrossRef]

21. Köhler, J.; Geels, F.W.; Kern, F.; Markard, J.; Wieczorek, A.; Alkemade, F.; Avelino, F.; Bergek, A.; Boons, F.; Fünfschilling, L.; et al. An agenda for sustainability transitions research: State of the art and future directions. Environm. Innov. Soc. Transit. 2019, 31, 1-32.

22. Tapinos, E.; Pyper, N. Forward looking analysis: Investigating how individuals 'do' foresight and make sense of the future. Technol. Forecast. Soc. Chang. 2018, 126, 292-302. [CrossRef]

23. Lee, C.; Chong, H.; Liao, P.; Wang, X. Critical Review of Social Network Analysis Applications in Complex Project Management. J. Manag. Eng. 2018, 34, 04017061. [CrossRef]

24. Burt, R.S. The Social Capital of Opinion Leaders. Ann. Am. Acad. Pol. Soc. Sci. 1999, 566, 37-54. [CrossRef]

25. Baer, M.; Evans, K.; Oldham, G.R.; Boasso, A. The social network side of individual innovation: A meta-analysis and path-analytic integration. Org. Psychol. Rev. 2015, 5, 191-223. [CrossRef]

26. René, R. Collaborative business modelling for systemic and sustainability innovations. Int. J. Technol. Manag. 2013, 63, 4-23.

27. Keiramo, M.; Heikkilä, E.; Jokinen, L.; Romanoff, J. A concept for collaborative and integrative process for cruise ship concept design—from vision to design by using double design spiral. In Marine Design XIII, Volume 1, Proceedings of the 13th International Marine Design Conference (IMDC 2018), Helsinki, Finland, 10-14 June 2018; Kujala, P., Lu, L., Eds.; Taylor \& Francis: London, UK, 2018; pp. 193-202.

28. Amara, R. The futures field: Functions, forms, and critical issues. Futures 1974, 6, 289-301. [CrossRef]

29. Abdolvand, N. A strategic alignment model for collaborative open innovation networks. Int. J. Bus. Innov. Res. 2019, 19, 1-28.

30. van Enst, W.I.; Runhaar, H.A.C. Working at the boundary: An empirical study into the goals and strategies of knowledge brokers in the field of environmental governance in the Netherlands. Sustainability 2017, 9, 1962. [CrossRef]

31. Gong, Y.; Kim, T.; Liu, Z. Diversity of social ties and creativity: Creative self-efficacy as mediator and tie strength as moderator. Hum. Relat. 2019, 73, 1664-1688. [CrossRef]

32. Hahl, O.; Kacperczyk, A.; Davis, J.P. Knowledge asymmetry and brokerage; Linking network perception to position in structural holes. Strategic Organ. 2016, 14, 118-143. [CrossRef]

33. Cross, R.; Borgatti, S.P.; Parker, A. Beyond answers: Dimensions of the advice network. Soc. Netw. 2001, 23, 215-235. [CrossRef]

34. Brown, J.S.; Duguid, P. Knowledge and Organization: A Social-Practice Perspective. Org. Sci. 2001, 12, 198-213. [CrossRef]

35. Milagres, R.; Burcharth, A. Knowledge transfer in interorganizational partnerships: What do we know? Bus. Prod. Manag. J. 2019, 25, 27-68. [CrossRef]

36. Chen, L. Supply chain collaboration for sustainability: A literature review and future research agenda. Int. J. Prod. Econ. 2017, 194, 73-87. [CrossRef]

37. Blome, C. Supply chain collaboration and sustainability: A profile deviation analysis. Int. J. Op. Prod. Manag. 2014, 34, 639-663. [CrossRef]

38. Dyllick, T. Clarifying the meaning of sustainable business: Introducing a typology from business-as-usual to true business sustainability. Organ. Environ. 2016, 29, 156-174. [CrossRef]

39. Gimenez, C. Sustainable operations: Their impact on the triple bottom line. Int J. Prod. Econ. 2012, 140, 149-159. [CrossRef]

40. Gong, Y.; Jia, F.; Brown, S.; Koh, L. Supply chain learning of sustainability in multi-tier supply chains. Int. J. Op. Prod. Manag. 2018, 38, 1061-1090. [CrossRef]

41. Brandenburg, M.; Gruchmann, T.; Oelze, N. Sustainable Supply Chain Management-A Conceptual Framework and Future Research Perspectives. Sustainability 2019, 11, 7239. [CrossRef]

42. Ben Arfi, W.; Hikkerova, L.; Sahut, J. External knowledge sources, green innovation and performance. Technol. Forecast. Soc. Chang. 2018, 129, 210-220. [CrossRef]

43. Klassen, R.D. Collaboration and evaluation in the supply chain: The impact on plant-level environmental investment. Prod. Op. Manag. 2003, 12, 336-352. [CrossRef]

44. Gimenez, C. Sustainable Supply Chains: Governance Mechanisms to Greening Suppliers. J. Bus. Eth. 2013, 116, 189-203. [CrossRef] 
45. Griffiths, A.; Petrick, J.A. Corporate architectures for sustainability. Int. J. Opt. Prod. Manag. 2001, 21, 1573-1585. [CrossRef]

46. Gould, R.V.; Fernandez, R.M. Structures of Mediation: A Formal Approach to Brokerage in Transaction Networks. Soc. Methodol. 1989, 19, 89-126. [CrossRef]

47. Jasny, L.; Lubell, M. Two-mode brokerage in policy networks. Soc. Netw. 2015, 41, 36-47. [CrossRef]

48. Hamilton, M.; Hileman, J.; Bodin, Ö. Evaluating heterogeneous brokerage: New conceptual and methodological approaches and their application to multi-level environmental governance networks. Soc. Netw. 2020, 61, 1-10. [CrossRef]

49. Borgatti, S.P. Network analysis in the social sciences. Science 2009, 323, 892-895. [CrossRef]

50. Schröpfer, V.L.M.; Tah, J.; Kurul, E. Mapping the knowledge flow in sustainable construction project teams using social network analysis. Eng. Constr. Archit. Manag. 2017, 24, 229-259. [CrossRef]

51. Uzzi, B.; Spiro, J. Collaboration and Creativity: The Small World Problem. Am. Soc. 2005, 111, 447-504. [CrossRef]

52. Perry-Smith, J. Social yet creative: The role of social relationships in facilitating individual creativity. Acad. Manag. J. 2006, 49, 85-101. [CrossRef]

53. Burt, R.S. Structural holes and good ideas. Am. J. Soc. 2004, 110, 349-399. [CrossRef]

54. Podolny, J.M.; Page, K.L. Network forms of organization. Ann. Rev. Soc. 1998, 24, 57-76. [CrossRef]

55. Inkpen, A.C.; Tsang, E.W.K. Social capital, networks, and knowledge transfer. Acad. Manag. Rev. 2005, 30, 146-165. [CrossRef]

56. Berges, F. Evolution of co-management: Role of knowledge generation, bridging organizations and social learning. J. Environ. Manag. 2009, 90, 1692-1702. [CrossRef] [PubMed]

57. Lazega, E. Teaming up and out? Getting Durable Cooperation in a Collegial Organization. Eur. Soc. Rev. 2000, 16, 245-266. [CrossRef]

58. Lorino, P. Pragmatism and Organization Studies; Oxford University Press: Oxford, UK, 2018.

59. De Jouvenel, B. Futuribles: Studies in Conjecture, edited by Bertrand de Jouvenel; The Pure Theory of Politics, by Bertrand de Jouvenel. Pol. Q. 2015. [CrossRef]

60. Poli, R. The implicit future orientation of the capability approach. Futures 2015, 71, 105-113. [CrossRef]

61. Warren, L.; Fuller, T. Capturing the Dynamics of Co-Production and Collaboration in the Digital Economy. Leonardo 2010, 43, 200-201. [CrossRef]

62. De Smedt, P.; Borch, K.; Fuller, T. Future scenarios to inspire innovation. Technol. Forecast. Soc. Chang. 2013, 80, 432-443. [CrossRef]

63. Rhisiart, M.; Miller, R.; Brooks, S. Learning to use the future: Developing foresight capabilities through scenario processes. Technol. Forecast. Soc. Chang. 2015, 101, 124-133. [CrossRef]

64. Slaughter, R.A. The foresight principle. Futures 1990, 22, 801-819. [CrossRef]

65. Ahlqvist, T.; Valovirta, V.; Loikkanen, T. Innovation policy roadmapping as a systemic instrument for forward-looking policy design. Sci. Publ. Pol. 2012, 39, 178-190. [CrossRef]

66. Schatzmann, J.; Schäfer, R.; Eichelbaum, F. Foresight 2.0-Definition, overview \& evaluation. Eur. J. Futures Res. 2013, 1, 1-15.

67. Milojević, I.; Inayatullah, S. Narrative foresight. Futures 2015, 73, 151-162. [CrossRef]

68. Rohrbeck, R.; Gemünden, H.G. Corporate foresight: Its three roles in enhancing the innovation capacity of a firm. Technol. Forecast. Soc. Chang. 2011, 78, 231-243. [CrossRef]

69. van der Duin, P.; Heger, T.; Schlesinger, M.D. Toward networked foresight? Exploring the use of futures research in innovation networks. Futures 2014, 59, 62-78. [CrossRef]

70. Könnölä, T. Facing the future: Scanning, synthesizing and sense-making in horizon scanning. Sci. Publ. Pol. 2012, 39, 222-231. [CrossRef]

71. Bravo, F. The disclosure of financial forward-looking information. Gend. Manag. Int. J. 2019, 34, $140-156$. [CrossRef]

72. Kivimaa, P. Government-affiliated intermediary organisations as actors in system-level transitions. Res. Policy 2014, 43, 1370-1380. [CrossRef]

73. Wältermann, M.; Wolff, G.; Rank, O. Formal and informal cross-cluster networks and the role of funding: A multi-level network analysis of the collaboration among publicly and privately funded cluster organizations and their managers. Soc. Netw. 2019, 58, 116-127. [CrossRef] 
74. Mirc, N.; Parker, A. If you do not know who knows what: Advice seeking under changing conditions of uncertainty after an acquisition. Soc. Netw. 2020, 61, 53-66. [CrossRef]

75. Hideg, E. Integral futures based on the paradigm approach. Futures 2013, 45, S6-S15. [CrossRef]

76. Bourgeois, R.; Penunia, E.; Bisht, S.; Boruk, D. Foresight for all: Co-elaborative scenario building and empowerment. Technol. Forecast. Soc. Chang. 2017, 124, 178-188. [CrossRef]

77. Godet, M. Future memories. Technol. Forecast. Soc. Chang. 2010, 77, 1457-1463. [CrossRef]

78. Miller, R. Learning, the Future, and Complexity. An Essay on the Emergence of Futures Literacy. Eur. J. Educ. 2015, 50, 513-523. [CrossRef]

79. Meyer, M. The Rise of the Knowledge Broker. Sci. Commun. 2010, 32, 118-127. [CrossRef]

80. Palonen, T.; Froehlich, D.E. Mixed methods social network analysis to drive organizational development. In Mixed Methods Social Network Analysis: Theories and Methodologies in Learning and Education; Froehlich, D.E., Rehm, M., Rienties, B.C., Eds.; Routledge: Abingdon, UK, 2020; pp. 87-100.

81. Burg, E. Framing and Interorganizational Knowledge Transfer: A Process Study of Collaborative Innovation in the Aircraft Industry. J. Manag. Stud. 2014, 51, 349-378. [CrossRef]

82. Miranda, J.; Pérez-Rodríguez, R.; Borja, V.; Wright, P.K.; Molina, A. Sensing, smart and sustainable product development (S3 product) reference framework. Int. J. Prod. Res. 2019, 57, 4391-4412. [CrossRef]

83. Borgatti, S.P.; Halgin, D.S. On Network Theory. Organ. Sci. 2011, 22, 1168-1181. [CrossRef]

84. Borgatti, S.P.; Everett, M.G.; Freeman, L.C. Ucinet 6 for Windows: Software for social network analysis. Harv. MA Anal. Technol. 2012, 6, 2-47.

85. Missaoui, R.; Kuznetsov, S.; Obiedkov, S. Formal Concept Analysis of Social Networks; Springer: Cham, Switzerland, 2017.

86. Sverrisson, Á. Translation networks, knowledge brokers and novelty construction: Pragmatic environmentalism in Sweden. Acta Soc. 2001, 44, 313. [CrossRef]

87. Agogué, M. Explicating the role of innovation intermediaries in the "unknown": A contingency approach. J. Strategy Manag. 2017, 10, 19-39. [CrossRef]

88. Keller, J.; Wong, S.; Liou, S. How social networks facilitate collective responses to organizational paradoxes. Hum. Relat. 2019, 73, 401-428. [CrossRef]

89. González-Moreno, Á.; Triguero, Á.; Sáez-Martínez, F.J. Many or trusted partners for eco-innovation? The influence of breadth and depth of firms' knowledge network in the food sector. Technol. Forecast. Soc. Chang. 2019, 147, 51-62. [CrossRef]

90. Chesbrough, H. Open Business Models: How to Thrive in the New Innovation Landscape; Harvard Business School Press: Boston, MA, USA, 2006.

91. West, J. Open innovation: The next decade. Res. Pol. 2014, 43, 805-811. [CrossRef]

92. Gloor, P.A.; Paasivaara, M.; Schoder, D.; Willems, P. Finding collaborative innovation networks through correlating performance with social network structure. Int. J. Prod. Res. 2008, 46, 1357-1371. [CrossRef]

Publisher's Note: MDPI stays neutral with regard to jurisdictional claims in published maps and institutional affiliations.

(C) 2020 by the authors. Licensee MDPI, Basel, Switzerland. This article is an open access article distributed under the terms and conditions of the Creative Commons Attribution (CC BY) license (http://creativecommons.org/licenses/by/4.0/). 